Journal of Social Sciences 3 (4): 190-196, 2007

ISSN 1549-3652

(C) 2007 Science Publications

\title{
The Determinants of Urban Household Poverty in Malaysia
}

\author{
T.Y. Mok, C. Gan and A. Sanyal \\ Commerce Division, P.O. Box 84, Lincoln University, Canterbury, New Zealand
}

\begin{abstract}
Since independence in 1950s Malaysia has been recognized as one of the more successful countries in fighting poverty: head count ratio came down to $5.7 \%$ by 2004 . However the recent process of rapid urbanization has led to an increase of urban poverty aggravated further by the 1997 Asian financial crisis. It is important to understand the nature and scale of urbanization, the various driving forces that affect it and the determinants of urban poverty as linked to this process. Our research identified the determinants of urban poverty in Malaysia using a logistic regression. A sample of 2,403 urban households from the 2004-05 Household Expenditure Survey (HES) had been used in this research. We first estimated the probability of households with specified characteristics to fall below Malaysia's official poverty line. Then we analyzed the sensitivity of the probability estimated to shift of the poverty line over a reasonable range. Results showed that human capital significantly reduced the chance of being poor while migrant workers are more prone to poverty. Household size, race and regions were also important determinants of poverty outcome in urban Malaysia. The findings had important policy implications for Malaysian government which had pledged to reduce overall poverty rate to $2.8 \%$ and eradicated hardcore poverty by 2010 under the Ninth Malaysian Plan.
\end{abstract}

Key words: Urban poverty, logistic regression, sensitivity analysis

\section{INTRODUCTION}

Malaysia had successfully reduced the incidence of poverty from 52.4-5.1\% between 1970 and 2002. Total number of poor households fell from 1.6 million to 267,000 over this period ${ }^{[1]}$. This trend was however getting disturbed, unnoticed at the time, by the country's fast economic growth and rapid urbanization of the 1990s. The urban population swelled from $30 \%$ in 1960 to $40 \%$ in 1980 and to $60 \%$ in $2000^{[26]}$. According to the United Nations Population Division, $78 \%$ of the country's population will be urbanized in 2030. The acceleration of urbanization has been accompanied by increase of urban poverty together with crowding, uneven distribution of development benefits and change in the ecology of urban environments.

When the economic boom (late 1980s and the 1990s) ended with the Asian financial crisis (1997), the country found itself in economic hardship, high unemployment and growing income inequality. The crisis of 1997 adversely affected the urban poor and migrant workers through job loss, rise of food prices and general inflation. Overall incidence of poverty increased from $6.8 \%$ in 1997 to $8.1 \%$ in 1999 . The number of poor households increased to 393,900 in
$1999^{[19]}$. Unemployment rate increased from 2.6- 3.9\% between 1996 and 1998 as the number of retrenched workers more than doubled from 8,000-19,000 between 1996 and 1997. Most retrenched workers were from manufacturing and construction sectors, thus affecting female workers, the urban poor and foreign workers who make up large parts of the labor force in these sectors ${ }^{[19]}$. In the country as a whole, income share of the bottom $40 \%$ fell from $14.5-13.5 \%$ while that of the top $20 \%$ increased from $50-51.2 \%$ between 1990 and $2004^{[15]}$. The government now faced the renewed challenge of reducing wealth and income inequality among and between ethnicities and regions and particularly in urban areas.

Given the changing dimensions and emerging new forms of poverty there is a need to re-examine urban poverty in Malaysia. This study identifies the determinants of urban poverty in Peninsular Malaysia, Sabah and Sarawak. Similar research has been previously conducted to analyze the determinants of poverty in women-headed households in the informal sector of Peninsular Malaysia ${ }^{[5]}$. However previous studies have used income to identify poor households. We have two problems with this procedure. First, the official poverty line in Malaysia is an consumption expenditure. Secondly data on household incomes are

Corresponding Author: C. Gan, Commerce Division, P.O. Box 84, Lincoln University, Canterbury, New Zealand Tel: 64-3-325-2811 Fax: 64-3-325-3847 
known to be less reliable than consumption data obtained from household expenditure surveys. Income is often under-reported and influenced by the timing of data collection. Expenditure data does not attract strategic under-reporting and collected for a year, it smoothes out fluctuations of intra-year ups and downs. We therefore compare a person's consumption expenditure with the poverty line to determine its poverty status. This agrees with the idea that poverty is the inability to attain a critical minimum amount of consumption. We study the effect of human capital, region of residence and other household characteristics on urban poverty using this benchmark.

Multiple regression model which used to be the main tool of analysis in this kind of studies has been criticized for a number of drawbacks and binary probit or logit models have been proposed as alternative and widely used ${ }^{[2,4,7,10,12,13,24,25]}$. Present research follows this methodology and we have used a logistical regression model explained in the next section.

The study is organized as follows: Section 2 discusses the empirical results. Conclusions and their implications are discussed in section 3.

\section{MATERIALS AND METHODS}

Data: Data for this research is obtained from Household Expenditure Survey (HES) conducted by the Department of Statistics, Government of Malaysia. The most recent HES of 2005 is our main source. This survey covers urban and rural areas of Peninsular Malaysia, Sabah and Sarawak except the interior areas of Sabah, Sarawak and the indigenous settlements (the Orang Asli). It uses stratified multi-stage design to choose its sample and the choice of sample size is determined by the relative standard error from previous surveys for every stratum and state. HES records a comprehensive expenditure of households including durables, semi durables and services for 12 months. In addition, it records a range of household characteristics. From this survey, a sample of 2,403 households in urban areas for the whole of Malaysia has been used for our research.

The definition of urban areas used in the survey was adopted from the Population and Housing Census of 2000. The Malaysian government defined urban as all gazetted areas with a population of 10,000 or more.

Model specification: We use a binomial logistic regression model given that the dependent variable is dichotomous: 0 when a household is above and 1 when below the poverty line. Predictor variables are a set of socioeconomic and demographic status indicators and human capital and dwelling endowment of the household. They contain both dichotomous and continuous variables. Let $\mathrm{Pj}$ denote the probability that the $\mathrm{j}$-th household is below the poverty line. We assume that $\mathrm{Pj}$ is a Bernouli variable and its distribution depends on the vector of predictors $\mathrm{X}$, so that:

$P_{j}(X)=\frac{e^{\alpha+\beta X}}{1+e^{\alpha+\beta X}}$

where, $\beta$ is a row vector and $\alpha$ a scalar. The logit function to be etimated is then written as:

$\ln \frac{P_{j}}{1-P_{j}}=\alpha+\sum_{i} \beta_{i} X_{i j}$

The logit variable $\ln \left\{\mathrm{P}_{\mathrm{j}} /\left(1-\mathrm{P}_{\mathrm{j}}\right)\right\}$ is the natural $\log$ of the odds in favor of the household falling below the poverty line. Equation 2 is estimated by maximum likelihood method and the procedure does not require assumptions of normality or homoskedasticity of errors in predictor variables.

\section{Demographic variables:}

Age_hh (-) = Age of household head (in years)

Sqage $(+) \quad=$ Age squared

Sex $(+) \quad=1$ if the household is a female, 0 otherwise

Child15 (+) $=$ Number of children under 15 years old

Madults $(+)=$ Number of male adults in household

Fadults $(+)=$ Number of female adults in household

Elderly $(+)=$ Number of elderly $(\geq 55$ years $)$

Marital $(+)=1$ if the head is non-married, 0 otherwise

Migrant $(+)=1$ if the household is a foreign migrant, 0 otherwise

Race $1=1$ if the household is Malay, 0 otherwise

Race $2=1$ if the household is Chinese, 0 otherwise

Race $3=1$ if the household is Indian, 0 otherwise

\section{Socioeconomic status:}

Industry_hh $(+)=1$ if the industry is secondary sector, 0 otherwise

Status (+) = $\quad 1$ if household doesn't own its living quarter; 0 otherwise

\section{Human capital variable:}

Hi_fed $(-)=$ Highest formal education obtained by household head (in years)

\section{Region variable:}

Region $1=1$ if Western region (incl. Kelantan, Terengganu, Pahang), 0 otherwise 
Region $2=1$ if Northern region (incl. Kedah, Penang, Perak, Perlis), 0 otherwise

Region 3 = 1 of Eastern region (incl. Sabah, Sarawak, Labuan), 0 otherwise

$$
\alpha=\text { intercept term }
$$

We have first estimated the model using the expenditure cut off point corresponding to Malaysia's official poverty line: per capita consumption expenditure of RM 155. This forms a benchmark. Then we have allowed some variation of the line and reworked the logistic estimates to study the robustness of qualitative conclusions. Due to the lack of definiteness in any poverty line specification, sensitivity analysis is important to ensure which predictors are robust over reasonable shift of the line ${ }^{[12,23]}$. Table 3 reports comparison over a range of poverty lines.

A priori hypotheses are indicated by (+) or (-) in the above specification. The age variable expects to account for the effect of work experience while the squared variable expects to capture the opposite effect of declining ability with age. Human capital is measured by education level. It has been identified in past research as an important determinant of household poverty. Marital, Madults and Fadults do not provide unambiguous a priori expectation because a married head or a larger family may face the prospect of extra burden as well as extra income and possible economy of scale. The signs put against them are based on the results of past research. Race variables represent the three main races of Malaysia.
Primary and secondary classification here does not conform to standard meaning of the two terms. Organizations in the primary sector are classified as large, diversified, capital intensive and offer higher pay and opportunities. In comparison, firms in secondary are smaller, labor-intensive and offer lower pay and opportunity for career enhancement ${ }^{[24]}$. It is believed that ceteris paribus a person employed in the secondary sector is more likely to be in poverty. Ownership status of dwelling is included because owning an asset would lower the risk of a household falling into poverty. It could function as shelter, as collateral for borrowing and be sold during bad times and helps income smoothing over time ${ }^{[12]}$.

Dummy variables have been used for regions, sex, marital status of household head, foreign migrant, races and industry.

\section{RESULTS AND DISCUSSION}

Table 1 presents the descriptive statistics of predictors by expenditure quartiles. It shows that means of the variables hi_fed, marital and Chinese increase over the quartiles, while status, child15, madult, fadult, elderly, migrant, Malays, region 1-3 fall with increasing per capita expenditure. For example, fewer higher educated households are in poverty than uneducated households. These distributions provide us with a priori expectations. In addition, the decreasing number of children, male adult, female adult and elderly households with increasing per capita expenditure shows the emergence of the nuclear family in higher income households in urban areas of Malaysia.

Table 1: Mean and standard deviation of predictors by expenditure quartiles

\begin{tabular}{lcccc}
\hline Variables & 25th percentile or less & 50th percentile or less & 75th percentile or less & Above 75th percentile \\
\hline Age_hh & $46.15(11.78)$ & $45.35(12.59)$ & $46.11(12.84)$ & $45.28(12.97)$ \\
Sex & $0.10(0.299)$ & $0.10(0.29)$ & $0.14(0.35)$ & $0.12(0.32)$ \\
Marital & $0.10(0.30)$ & $0.11(0.32)$ & $0.12(0.33)$ & $0.18(0.38)$ \\
Hi_fed & $5.10(2.815)$ & $6.41(2.79)$ & $6.82(3.03)$ & $8.09(3.00)$ \\
Industry & $0.33(0.471)$ & $0.31(0.46)$ & $0.31(0.46)$ & $0.36(0.48)$ \\
Status & $0.44(0.497)$ & $0.36(0.48)$ & $0.32(0.47)$ & $0.32(0.47)$ \\
Child15 & $3.12(1.88)$ & $2.17(1.60)$ & $1.48(1.29)$ & $1.08(1.29)$ \\
Madult & $1.49(1.07)$ & $1.48(1.31)$ & $1.35(0.97)$ & $1.18(0.86)$ \\
Fadult & $1.56(0.81)$ & $1.50(1.03)$ & $1.43(0.99)$ & $1.28(0.84)$ \\
Elderly & $0.51(0.77)$ & $0.43(0.70)$ & $0.48(0.78)$ & $0.42(0.75)$ \\
Migrant & $0.06(0.23)$ & $0.01(0.10)$ & $0.02(0.14)$ & $0.01(0.08)$ \\
Malays & $0.58(0.49)$ & $0.58(0.49)$ & $0.5(0.5)$ & $0.43(0.49)$ \\
Chinese & $0.15(0.36)$ & $0.22(0.41)$ & $0.34(0.47)$ & $0.43(0.49)$ \\
Indians & $0.08(0.27)$ & $0.12(0.33)$ & $0.08(0.27)$ & $0.10(0.29)$ \\
Region 1 & $0.15(0.36)$ & $0.11(0.32)$ & $0.08(0.27)$ & $0.04(0.19)$ \\
Region 2 & $0.19(0.39)$ & $0.23(0.42)$ & $0.22(0.42)$ & $0.15(0.36)$ \\
Region 3 & $0.25(0.43)$ & $0.14(0.34)$ & $0.13(0.33)$ & $0.12(0.33)$
\end{tabular}

Notes: Mean is the main entry and standard deviation is in parenthesis; Source: Calculated from the survey data 
Table 2: Logistic model (Poverty Line RM155)

\begin{tabular}{lcc}
\hline Variables & Estimated coefficient & Marginal effect \\
\hline Constant & -1.09650 & - \\
Age & -0.10860 & -0.001600 \\
Sqage & 0.00096 & 0.000014 \\
Hi_fed $*$ & -0.31490 & -0.004700 \\
Sex & 0.03590 & 0.000550 \\
Child15 * & 0.57330 & 0.008620 \\
Madults * & 0.40220 & 0.006050 \\
Fadults * & 0.26010 & 0.003910 \\
Elderly & 0.30870 & 0.004640 \\
Status & 0.03690 & 0.000560 \\
Marital & -0.97420 & -0.011100 \\
Industry & -0.05710 & -0.000850 \\
Migrant * & 1.42460 & 0.042800 \\
Malays & 0.20010 & 0.003000 \\
Chinese $*$ & -1.23060 & -0.015100 \\
Indians & -0.54640 & -0.006600 \\
Region 1 $*$ & 1.04690 & 0.023300 \\
Region 2 & 0.41240 & 0.006900 \\
Region 3 $*$ & 0.77090 & 0.013900 \\
No. of observations & & $2,403.000000$ \\
LR statistic $\left(\chi^{2}\right)$ & & $313.955000^{*}$ \\
Degrees of freedom & & 18.000000 \\
Log likelihood & & -342.904000 \\
McFadden R & & 0.314030 \\
\% Predicted right & & $94.800000 \%$ \\
\hline Not Mat M & &
\end{tabular}

Note: Marginal effect is evaluated at the mean value of predictor variables. For dummy variable, marginal effect is $\mathrm{P}|1-\mathrm{P}| 0$; *: Denote statistically significant at $5 \%$ significance level

Determinants of urban poverty: The estimates of the logistic regression are shown in Table 2. In general, the logit model fitted the data quite well. The chi-square test strongly rejects the hypothesis of no explanatory power and the model correctly predicted $94.8 \%$ of the observations. Furthermore, Hi_fed, Child15, Madults, Fadults, Migrant, Region 1 and Region 3 are statistically significant and the signs on the parameter estimates support expectations. The variable Chinese supports the observations of Table 1 .

The results show education is an important determinant, which supports the findings of most previous researches ${ }^{[9,12,21,23,24]}$. Additional insight can be obtained through analysis of the marginal effects calculated as the partial derivatives of the non-linear probability function, evaluated at each variable's sample mean ${ }^{[11]}$. For example, an increase of a year of formal education after the mean number of years of the sample reduces the probability of a household falling into poverty by 0.0047 . The results also show that a higher proportion of children under 15 years of age, female and male adults in the household increase the probability of a household falling into poverty. Number of children is generally found to be associated with poverty in most studies cutting across the developing world. Secondly, both genders (almost) equally increase the probability of being poor thus indicating low level of gender discrimination in urban Malaysia. This could be the result of local governments providing childcare assistance to encourage women to work and the work of Non-Government Organizations (NGOs) towards female-empowerment.

The variable migrant displays the highest marginal effect, $4.3 \%$. This supports the a priori expectation based on the observation that most migrants do not receive social benefits and are not protected by labor laws. In addition, this finding corroborates observation by $^{[22]}$ that foreign workers in Malaysia earn less than their Malaysian counterparts. Thus, the existence of market segmentation and discrimination in the job market has increased the risk of foreign workers falling into poverty.

Notably, the variable Chinese has a negative and significant coefficient. This suggests relatively higher employment and business opportunities for the Chinese compared to other races. $\operatorname{Lim}^{[14]}$ found that the incidences of poverty in three new Chinese villages were lower compared to the average for Peninsular Malaysia. He believed that this was due to their strong ability of being able to adapt well to changing environment. Milanovic ${ }^{[17]}$ found that adjusted earnings of the Chinese are 25\% higher than those of Malays. Thus, it is believed that the adaptability and higher earning by the Chinese enable them to escape poverty.

Urban households living in Region 1 and 3 are found to be at a higher risk compared to other regions. Milanovic $^{[17]}$ found that Penang in Region 2 and central region displayed the highest average earnings and growth rates between 1983 and 1997 compared to other regions. Therefore, with the low average earnings, the urban poor in Region 1 and 3 would certainly face hardship, especially with the rising cost of living.

Contrary to expectation, industry status is negatively correlated with poverty though statistically insignificant. This possibly shows the importance of labor-intensive activities in helping the relatively poor escape from absolute poverty. Interestingly, the results show that owning a house does not significantly reduce the probability of being poor in urban Malaysian context. Further analysis of ownership status and the type of housing is required to establish its link with poverty. Without further information and data this linkage could not be examined. Finally, the age and life-cycle effect on poverty is found to be statistically insignificant.

Sensitivity analysis: The above findings are specific to the benchmark poverty line. To determine if they are robust we re-estimated the logistic regression with limited shifts of the poverty line. Table 3 shows the results for $\pm 20 \%$ shift of the benchmark line of RM 155 . 


\section{J. Social Sci., 3 (4): 190-196, 2007}

Table 3: Re-estimation with $\pm 20 \%$ shift of poverty line

\begin{tabular}{lcc}
\hline Variables & PL $=$ RM 124 & PL $=$ RM 186 \\
\hline Constant & -4.0468 & -1.5841 \\
Age & 0.0988 & -0.0568 \\
Sqage & 0.0009 & 0.0004 \\
Hi_fed & $-0.3324^{*}$ & $-0.2954^{*}$ \\
Sex & 0.3465 & 0.0335 \\
Child15 & $0.7394^{*}$ & $0.6073^{*}$ \\
Madults & $0.3587^{*}$ & $0.3494^{*}$ \\
Fadults & 0.1977 & 0.1672 \\
Elderly & 0.6722 & $0.4641^{*}$ \\
Status & 0.0169 & 0.1496 \\
Marital & -0.8629 & -0.6367 \\
Industry & -0.0050 & -0.1684 \\
Migrant & $2.7064 *$ & $1.2132^{*}$ \\
Malays & 0.7609 & 0.2184 \\
Chinese & -1.4841 & $-1.7436^{*}$ \\
Indians & 1.3333 & -1.0789 \\
Region 1 & 1.2836 & $1.0835^{*}$ \\
Region 2 & -28.5546 & $0.6135^{*}$ \\
Region 3 & $1.4923^{*}$ & $0.8639^{*}$ \\
LR statistic $\left(\chi^{2}\right)$ & 195.3880 & 453.5390 \\
\hline *. Denote statistically significant at 5\% significant level
\end{tabular}

Table 4: Upward shifts of the poverty line

\begin{tabular}{lcccc}
\hline Variables & $\begin{array}{l}\mathrm{PL}=5 \% \\
\text { above }\end{array}$ & $\begin{array}{l}\mathrm{PL}=10 \% \\
\text { above }\end{array}$ & $\begin{array}{l}\mathrm{PL}=15 \% \\
\text { above }\end{array}$ & $\begin{array}{l}\mathrm{PL}=30 \% \\
\text { above }\end{array}$ \\
\hline Constant & -1.2769 & -0.8010 & -0.6879 & -1.1086 \\
Age & -0.0876 & -0.1147 & -0.1043 & -0.0342 \\
Sqage & 0.0007 & 0.0009 & 0.0008 & 0.00002 \\
Hi_fed & $-0.3026^{*}$ & $-0.3012^{*}$ & $-0.3068^{*}$ & $-0.3048^{*}$ \\
Sex & -0.0365 & 0.2335 & 0.1867 & 0.3419 \\
Child15 & $0.6202^{*}$ & $0.6281^{*}$ & $0.6424^{*}$ & $0.5730^{*}$ \\
Madults & $0.3548^{*}$ & $0.3630^{*}$ & $0.3668^{*}$ & $0.2943^{*}$ \\
Fadults & $0.2708^{*}$ & $0.2701^{*}$ & 0.1954 & $0.2495^{*}$ \\
Elderly & $0.4478^{*}$ & $0.4349^{*}$ & $0.4437^{*}$ & $0.6786^{*}$ \\
Status & 0.2031 & 0.2769 & 0.1031 & 0.2393 \\
Marital & -0.7155 & $-0.8668^{*}$ & -0.7964 & $-0.9808^{*}$ \\
Industry & -0.0579 & -0.0838 & -0.1614 & 0.0007 \\
Migrant & $1.3751^{*}$ & $1.2520^{*}$ & $1.4004^{*}$ & $0.7500^{*}$ \\
Malays & 0.0840 & 0.2035 & 0.2722 & -0.2467 \\
Chinese & $-1.4021^{*}$ & $-1.4649^{*}$ & $-1.5830^{*}$ & $-2.3203^{*}$ \\
Indians & -0.9208 & -0.9716 & -0.8163 & $-1.3912^{*}$ \\
Region 1 & $1.0725^{*}$ & $1.1668^{*}$ & $1.1338^{*}$ & $1.1510^{*}$ \\
Region 2 & 0.2748 & 0.4357 & 0.5191 & $0.6296^{*}$ \\
Region 3 & 0.6310 & $0.8015^{*}$ & $0.7993^{*}$ & $0.7554^{*}$ \\
LR statistic & 369.7140 & 399.4390 & 436.8960 & 540.0000 \\
\hline
\end{tabular}

*: Denote statistically significant at 5\% significant level

Table 3 shows the effect of education on poverty is dominant and robust. This implies education reduces the probability of a household being poor, regardless of the poverty line used. Effects of other variables such as the number of children and the proportion of male adults in a household, foreign migrant-headed household and households living in Region 3 are also statistically significant and robust.

However, the coefficient estimates for Chinese is insignificant at $-20 \%$ poverty line but significant at the $+20 \%$ poverty line. Similar findings are found for the coefficient estimates of Region 1 which are statistically significant only at the higher poverty line.
For our enquiry sensitivity to upward shift of the poverty line is more germane. The official poverty line refers to the country as a whole. It is reasonable to expect a higher poverty line in urban areas than the national average. With this in mind we tried to understand the sensitivity of estimated coefficients to upward shift of the poverty line in small steps. The results are shown in Table 4. Effects of education, number of children, number of male adults, foreign migrant-headed household, Chinese household and households living in Region 1 on poverty are robust over the shifts. The coefficient estimate of Region 3 is statistically insignificant with a shift of $5 \%$ but becomes significant again for further shifts.

\section{CONCLUSION}

Present study shows that the generally observed positive relation between earnings and higher education in Malaysia ${ }^{[6]}$ extends around the threshold of poverty. This result supports the Malaysian government's strong emphasis on education and training in its poverty eradication programs. The results further shows that larger families are more prone to poverty, given that child 15, Madults and Fadults are all significant correlates of poverty. Looking at the composition of families, households with more members below 15 are more prone. Foreign migrant-headed households and households living in Region 3 are also found more prone to be poor in urban areas.

The locational dimension of poverty is highlighted by the finding that those living in Regions 1 and 3 face higher risk of being poor. From the HES, it is found that the state of Sabah in Region 3 and Terengganu in Region 1 have the highest incidence of poverty. Most of the poor in these states work in construction and sizeable numbers in fishery (21\% in Terengganu) and manufacturing (23\% in Sabah). It is imperative that the government looks into wages, working conditions and productivity in these operations.

For policy it is important to note that the probability of being poor is negatively correlated with secondary sector employment. This sector is characterized by small establishments and laborintensive production. Local governments of Sabah of Region 3 and Terengganu of Region 1 could offer incentives for setting up small/medium enterprises with low-cost, labor-intensive technology. $\mathrm{As}^{[20]}$ notes extending government loans to this sector alone may not be sufficient as the units face organizational and marketing constraints. The government should provide consultancy support at the grass root level and increase its outreach, possibly with help from NGOs. 
As we reported the variable migrant has the highest marginal contribution to the risk of poverty. Government policy towards migrant workers should be seriously thought through. Ali ${ }^{[18]}$ has found inflow of foreign workers is related to Malaysia's economic growth. Rapid growth has led to large illegal inflow from neighboring countries such as Indonesia, Thailand, Vietnam and Myanmar. These workers are more vulnerable to economic downswings. With no government support, they easily fall into poverty. Ali ${ }^{[18]}$ estimated the incidence of poverty among migrant workers at $12.6,17.5$ and $14.2 \%$ in 1995,1997 and 1999 respectively. The size of immigrant workers is large (1.7 million in 2005) and if the government starts to deport them as currently envisaged, it is expected to fall only to 1.5 million by $2010^{[15]}$. With such large numbers at issue, the government has to develop a comprehensive policy towards migrant workers. Unless the government seeks alternatives to reduce its dependence on foreign workers, foreign workers' welfare has to be addressed in order to reduce poverty and resulting social problems in urban areas. Inevitably, tackling the social problems caused by immigrants require resources which in turn compromise the government's poverty alleviation effort.

Problem arising from the country's dependence on migrant workers for domestic service can be partially addressed by training local women for this sector. Noting that significant welfare measures are already in place for local population, encouraging locals to work in domestic services could have a significant effect on overall poverty. Women's workforce participation ratio is high and still increasing: $46 \%$ in $2006^{[15]}$. From the HES survey, 77 and $48 \%$ of females in Region 1 and 3 respectively are engaged in secondary sectors. Urban domestic services provide steadier employment and better wages than these secondary sector jobs. Reluctance of households to move across the country has to be overcome with proper incentives.

Our results also show that the urban elderly (above the age of retirement) face greater risk of being poor. The coefficient estimate is statistically significant for poverty lines above RM 155. Ageing population is prone to distress in many developing countries and Malaysia is no exception. Longer life expectancy (70 years at present) coupled with increasing medical cost and inadequate social support leads to an increase of the probability of falling into poverty. Social support for retirement is a crying need in Malaysia. According to the Employee Provident Fund (EPF) annual report of 2005, 90\% of workers have less than RM 100,000 contributed to the EPF savings, which is insufficient to see them through 20 years upon retirement. It is further estimated that less than $5 \%$ of people are financially prepared to retire. In addition, only $40 \%$ of Malaysians have life insurance to secure themselves ${ }^{[8]}$. These figures are expected to be significantly lower for households close to the poverty line. The government should seriously review the national retirement and old age support policies and encourage the younger generations to save for retirement.

Though the Malaysian society as a whole is moving to smaller families, there are large numbers of dependents in poor households in high cost urban areas. The government should identify urban households with a high proportion of children to provide them with education subsidies or tax relief. Currently RM 1,000 tax relief per child is given to working married adults for their children under 18 years of age. With the rising cost of living in urban areas, this amount may not be sufficient for them to meet their basic needs.

As the country approaches the tenth anniversary of the Asian financial crisis, marking a decade that has seen urban poverty rise steadily, it is important for the government to understand the causes of urban poverty in order to intervene in it. This research has been aimed at providing some insights to policy-makers who propose to reduce overall poverty rate to $2.8 \%$ and eradicate hardcore poverty by 2010 under the Ninth Malaysian Plan.

\section{ACKNOWLEDGEMENT}

The researchers wish to thank Dr Baiding $\mathrm{Hu}$ for assistance and comments with data processing.

\section{REFERENCES}

1. Ahmad, N., 2005. The role of government in poverty reduction. Proceeding of the National Seminar on Poverty Eradication through Empowerment, Aug. 23, Kuala Lumpur.

2. Alderman, H. and M. Garcia, 1993. Poverty, Household Food Security and Nutrition in Rural Pakistan. Research Report 1996, Washington DC., IFPRI. http://ideas.repec.org/p/fpr/resrep/96.html

3. Ariffin, J., 1994. Poverty: Conceptual Underpinnings, Trends and Patterns in Malaysia. A In: Literature Review, J. Ariffin (Ed.). Poverty Amidst Plenty, Pelanduk Publications, Kuala Lumpur, pp: 1-24.

4. Bardhan, P.K., 1984. Land, Labor and Rural Poverty. Oxford University Press, Delhi, ISBN: 10: 0231053886.

5. Berma, M. and F. Shahadan, 1994. Poverty, Household Status and Women in the Informal Sector: A Structural Analysis. In: Poverty Amidst Plenty, Ariffin, J. (Ed.). Pelanduk Publications, Kuala Lumpur, pp: 207-227. 
6. Chung, T.P., 2004. The returns to education over time: The Malaysian outlook, 1984-1997. Proceeding of the 4th International Conference on Malaysian Studies, Aug. 3-5, University Kebangsaan Malaysia, Bangi.

7. Coulombe, H. and A. McKay, 1996. Modeling determinants of poverty in Mauritania. World Develop., 24: 1015-1031. http://ideas.repec.org/a/eee/wdevel/v24y1996i6p10 15-1031.html

8. Counting on the nest egg, 2007. The Star. Retrieved May 27-27, 2007, from http://www.thestar.com.my

9. Datt, G. and D. Jolliffe, 2005. Poverty in Egypt: Modeling and policy simulations. Econ. Develop. Cultural Change, 53: 327-346. http://ideas.repec.org/a/ucp/ecdecc/y2005v53i2p32 7-46.html

10. Gaiha, R., 1988. On Measuring the Risk of Poverty in Rural India. In: Rural Poverty in South Asia, Srinivasan, T.N. and P. Bardhan (Eds.). Columbia University Press, New York.

11. Greene, W.H., 1990. Econometric Analysis. Macmillan Publishing Co., New York.

12. Grootaert, C., 1997. The Determinants of poverty in cote d'ivoire in the 1980s. J. Afr. Econ., 6: 169-196. http://jae.oxfordjournals.org/cgi/content/abstract/6/ $2 / 169$

13. Lanjouw, P. and N. Stern, 1991. Poverty in Palanpur. World Bank Econ. Rev., 5: 23-55. http://eprints.lse.ac.uk/4128/

14. Lim, H.F., 1994. Poverty and Household Economic Strategies in Malaysian New Villages. Pelanduk Publications, Petaling Jaya, ISBN: 10: 9679784967, pp: 250.

15. Malaysia, 2006. Ninth Malaysia Plan, 2006-2010. Government Printer, Putrajaya. http://www.epu.gov.my/rm9/english/Index.pdf

16. Malaysia, 2006. Report on Household Expenditure Survey Malaysia 2004/05. Department of Statistics, Malaysia.

http://www.statistics.gov.my/eng/index.php?option=com _content\&view=article\&id=307:report-on-householdexpenditure-survey-200405\&catid=47:report-onhousehold-expenditure-survey-\&Itemid=12
17. Milanovic, B., 2001. Inequality and Determinants of Earning in Malaysia, Asia and Pacific Forum on Poverty: Reforming Policies and Institutions for Poverty Reduction, Asian Development Bank, Feb. 5-9, Manila. http://www.adb.org/Poverty/Forum/pdf/Milanovic1.pdf

18. Ali, M.N., 2004. Foreign workers and poverty in Malaysia. Proceeding of the 4th International Malaysian Studies Conference, Aug. 3-5, University Kebangsaan Malaysia, Bangi.

19. Nair, S., 2005. Causes and consequences of poverty in Malaysia. Proceeding of the National Seminar on Poverty Eradication through Empowerment, Aug. 23, Kuala Lumpur.

20. Rakodi, C., 1995. Poverty lines or household strategies?: A review of conceptual issues in the study of urban poverty. Habitat Int., 19: 407-426. DOI: 10.1016/0197-3975(95)00037-G

21. Rodriguez, A.G. and S.M. Smith, 1994. A comparison of determinants of urban, rural and farm poverty in Costa Rica. World Develop., 22: 381-397.

http://ideas.repec.org/a/eee/wdevel/v22y1994i3p38 1-397.html

22. Ruppert, E., 1999. Managing Foreign labor in Singapore and Malaysia: Are there lessons for GCC Countries? World Bank, Policy Research Working Paper WPS 2053, Washington. http://papers.ssrn.com/sol3/papers.cfm?abstract_id $=597250$

23. Serumaga-Zake, P. and W. Naude, 2002. The Determinants of rural and urban household poverty in the North West province of South Africa. Develop. Southern Afr., 19: 561-572. DOI: 10.1080/0376835022000019392

24. Thompson, A. and D.R. McDowell, 1994. Determinants of poverty among workers in metro and nonmetro areas of the South. Rev. Black Political Econ., 22: 159-177. DOI: 10.1007/BF02689985

24. World Bank, 2005. Introduction to Poverty Analysis. Washington DC.

25. World Bank, 2007. East Asia 10 Years After the Financial Crisis. Washington DC. 